\title{
ОСОБЛИВОСТІ ВИНИКНЕННЯ ТРАВМИ АРТЕРІЙ У ДІТЕЙ
}

\author{
В. Ф. Петров \\ Львівська обласна клінічна лікарня \\ PECULIARITIES OF OCCURRENCE OF THE ARTERIES TRAUMA IN CHILDREN \\ V. F. Petrov \\ Lviv Regional Clinical Hospital
}

Травма артерій у дітей становить $0,42-$ $4,5 \%$ в структурі травми у потерпілих віком до $16-18$ років [1 - 6]. Великі травматологічні центри США та Європи щороку надають допомогу приблизно 5 дітям 3 приводу пошкодження судин $[7,8]$. Невисока частота цього грізного ускладнення підвищує інтерес до кожного клінічного спостереження.

У дітей перших років життя ушкодження артерій виникає переважно за ятрогенної, у старшому віці - неятрогенної травми [5, 9-14].

Ятрогенна травма. Ятрогенія становить від 33 до 50\% всіх уражень артерій у дітей $[9,11,15]$. Ятрогенна травма артерій переважно проникна $[9,13]$.

Імовірність ушкодження стегнових артерій під час ендоваскулярного втручання у дітей перших років життя становить $30 \%$, у віці $7-10$ років - $2-7 \%[9,11,13$, 16]. Відтак, $67 \%$ всіх артеріальних ускладнень педіатричних ендоваскулярних втручань виникають у дітей першого року життя [16]. Ятрогенна травма артерій у дітей частіше виникає на нижній кінцівці, ніж на верхній [17, 18].

У дітей першого року життя діаметр стегнової артерії не перевищує кількох міліметрів, тому за відносно широкого катетера, встановленого в просвіт судини, травмується її ендотелій [16]. Під час введення катетера в судину внутрішня оболонка відшаровується від середньої, а при видаленні катетера з стінки зривають фі- бринову плівку. Оголена внутрішня оболонка і фібриновий згусток зумовлюють локальний тромбоз та гостру ішемію тканин кінцівки $[7,9,19,20] .3$ огляду на патофізіологію посткатетеризаційного тромбозу, факторами ризику є малий вік і маса тіла, велике співвідношення діаметра катетера та артерії [21]. Виникненню тромбозу сприяють гіповолемія, поліцитемія, шоковий стан гемодинаміки, гіперкоагуляційні вроджені чинники [15].

Пошкодження артерій під час пункції вен виникають у $0,03 \%$ дітей, i, як правило, їх не реєструють, це зумовлює утворення артеріовенозних нориць [17].

Гострий кінець медичного інструмента може розрізати чи надрізати стінку артерії, виникає кровотеча, об'єм якої залежить не тільки від тяжкості травми, а й анатомічних меж артерії, кровотеча в заочеревинний простір масивна, в анатомічному футлярі кінцівки - більш обмежена [18]. Якщо інструментом здійснений наскрізний прокол судини, кровотеча може обмежитись утворенням псевдоаневризми $[7,9,18$ $20,22]$.

Іноді травма артерій виникає під час ортопедичних, нейрохірургічних, торакальних, абдомінальних, онкологічних операцій, інвазивного моніторингу артеріального тиску, пункції артерій для визначення вмісту газів у крові або внаслідок помилкового проколу при встановленні центрального венозного катетера в умовах палат інтенсивної терапії, канюляції судин

Таблиця 1. Локалізація неятрогенної травми артерій у дітей

\begin{tabular}{|l|c|c|c|c|c|}
\hline \multirow{2}{*}{ Автори, рік публікації } & \multirow{2}{*}{$\begin{array}{c}\text { Кількість } \\
\text { спостережень }\end{array}$} & \multicolumn{4}{|c|}{ Частота виявлення, \%, локалізація } \\
\cline { 3 - 7 } & & $\begin{array}{c}\text { верхня } \\
\text { кінцівка }\end{array}$ & $\begin{array}{c}\text { нижня } \\
\text { кінцівка }\end{array}$ & тулуб & $\begin{array}{c}\text { шия } \\
\text { і голова }\end{array}$ \\
\hline Allen C. J. і співавт. [1] & 74 & \multicolumn{2}{|c|}{50,5} & 29,1 & 20,4 \\
\hline Barmparas G. і співавт. [2] & $\begin{array}{c}1138 \\
\text { (артерії та вени) }\end{array}$ & 36 & 19 & 37 & 9,9 \\
\hline Corneille M. G. і співавт. [3] & 111 & 37 & 25 & 31 & 6,9 \\
\hline Klinker D. B. і співавт. [5] & 81 & 37 & 31 & 15 & 17 \\
\hline $\begin{array}{l}\text { Wahlgren C.-M., Kragsterman B. } \\
\text { співавт. [14] }\end{array}$ & 198 & 66 & 28 & 5,6 & 0,5 \\
\hline
\end{tabular}

для екстракорпоральної мембранної оксигенації [7, 18 - 22]. Наведені спостереження ятрогенії, що виникла у внутрішньоутробному періоді життя як наслідок амніоцентезу (артеріовенозна нориця між підколінними артерією та веною), під час кесаревого розтину (розрив клубових артерій) $[21,23]$.

Неятрогенна травма. У дітей перших років життя неятрогенне пошкодження артерій виникає відносно рідко. 3 віком і в міру збільшення активності дитини підвищується ймовірність ушкодження судин від порізів склом, травми, у старшому віці - від падіння, спортивних і вогнепальних поранень, дорожно-транспортних пригод $[2,4,24]$.

Близько $80 \%$ неятрогенних пошкоджень артерій у дітей виникають у віці старше 5 років [10]. У малят віком до 2 років частота неятрогенної травми артерій становить $0,9-4 \%$, до 6 років $-22-35 \%$, $7-12$ років - $34-74 \%, 12-15$ років - 35 $-86 \%[1,3,4,9,14]$.

Під час військових дій частота травми судин у дітей збільшується у $5-7$ разів, про що свідчать повідомлення в літературі $[9,20,25,26]$. Ризик травми судин збільшується під час природних катаклізмів [14].

В перші роки життя у хлопчиків та дівчаток травма виникає з однаковою частотою, у віці 5 - 8 років - суттєво переважають хлопчики - до 75 - $81 \%[5,9,10,12$ $14,20]$.

Локалізація неятрогенної травми артерій у дітей наведена у табл. 1 .

Отже, у дітей переважає травма артерій верхньої кінцівки, менш поширена - судин шиї та голови.

Згідно реєстру National Trauma Data Bank (США), у дітей частіше виявляють травму судин верхніх кінцівок $(35,7 \%$ у дорослих - 26,0\%), рідше - судин грудної порожнини - відповідно у 13,2 і 24,4\% [2]. Це можна пояснити відмінностями співвідношення розмірів тулуба і кінцівок у дітей та дорослих, еластичністю грудної 
клітки, віковими особливостями моторної активності $[2,5,13,14]$.

Деякі захворювання артерій у дітей виникають досить рідко - розшарування стінки сонних артерій за непроникної травми шиї, гостра травма сонних артерій, травматичний розрив грудної частини аорти [27 - 29]. Причини неятрогенної травми артерій у дітей наведені у табл. 2.

Аналізуючи дані табл. 2, спостерігаємо приблизно однакову частоту проникної та непроникної травми артерій у дітей. За проникної травми частіше виникає ушкодження артерій верхніх кінцівок, за непроникної - нижніх.

3 проникних травм переважали вогнепальні та колючо-ріжучі поранення, 3 непроникних - падіння або події, пов'язані $з$ автомобільним транспортом $[1,5]$. В окремих повідомленнях автори звертають увагу на певні види пошкодження: травма артерій при вогнепальних пораненнях відзначена у 70,8\% спостережень [32]; пошкодження артерій верхніх кінцівок внаслідок порізів склом - у 53\% [33]. У дітей раннього віку ураження судин спричинене тупою травмою, коли артерії пошкоджуються уламками кісток; у старшому віці гострою травмою, вогнепальним пораненням, падінням [2, 14, 31, 34, 35]. Перелом дистального відділу стегнової кістки, вивих колінного і ліктьового суглобів, травма плато великогомілкової кістки, супракондилярний перелом плечової кістки пов'язані з більшим ризиком пошкодження судин [10, 14, 24].

Під час військових дій пошкодження судин у дітей спричинене переважно вибухами (у 58\%) або вогнепальними пораненнями (у 37\%) [20, 26, 36]. Відзначені національні особливості причин травми артерій: в США частота смерті дітей, спричиненої вогнепальними пораненнями, збільшилася з $11 \%$ - у 80 -ті роки до $20 \%$ - у 2000-ні роки, в Індії частота травми судин від вогнепального поранення дітей ста-

Таблиця 2. Причини неятрогенної травми артерій у дітей

\begin{tabular}{|l|c|c|}
\hline \multicolumn{1}{|c|}{ Автори, рік публікації } & $\begin{array}{c}\text { Кількість } \\
\text { спостережень }\end{array}$ & $\begin{array}{c}\text { Проникна / непроникна } \\
\text { травма, що спричинила } \\
\text { пошкодження артерій, \% }\end{array}$ \\
\hline Klinker D. B. і співавт. [5] & 81 & $68 / 32$ \\
\hline Silva M. A. М. і співавт. [13] & 35 & $62 / 38$ \\
\hline Corneille М. G. і співавт. [3] & 111 & $58 / 42$ \\
\hline Allen C. J. і співавт. [1] & 74 & $58 / 42$ \\
\hline Harris L. M., Hordines J. i співавт. [30] & 19 & $58 / 42$ \\
\hline Shah S. R. і співавт. [31] & 42 & $55 / 45$ \\
\hline Jaipura J. і співавт. [4] & 83 & $44 / 56$ \\
\hline Barmparas G. і співавт. [2] & 1138 & $42 / 58$ \\
\hline
\end{tabular}

новить лише 3\% [1, 4, 37]. У США у дітей, старших 5 років, збільшилася частота травми артерій від вогнепального поранення, зокрема, внаслідок самоушкодження [2].

Ушкодження судин поділяють на проникні, непроникні та їх наслідки - посттравматичну псевдоаневризму, артеріовенозну норицю, хворобу кукси судини, ішемічну контрактуру [38]. Тупа травма імовірніше спричиняє непроникне ушкодження артерій - дефекти внутрішньої оболонки, інтрамуральну гематому, оклюзію; за гострої травми виникає пошкодження стінки артерій чи повне пересічення судини.

3 неятрогенних травм артерій бічні надриви спостерігали у 13 (36\%) постраждалих, повні відриви - у 10 (27\%), посттравматичну псевдоаневризму - у 8 (22\%), забій - у 5 (13\%) [9]. Під час операції на артеріях кінцівок повний розрив виявлений у 45 (60\%) постраждалих, бічний надрив - у 17 (19\%), оклюзія або тромбоз - у 15 (17\%), спазм - у 8 (9\%), псевдоаневризма - в $1(1 \%)$ [4]. Травма артерій нижніх кінцівок представлена повним відривом - у 50 - 96\% постраждалих, надривом - у 4 - 37\%, посттравматичною псевдоаневризмою - у 3 - 22\%, забій діагностували у $6-13 \%$ дітей $[24,39]$.
У дітей проникна і непроникна травма судин часто супроводжується спазмом $[40,41]$. Схильність до артеріоспазму зумовлена малим діаметром судин, більшою кількістю волокон еластину і гладеньком'язових клітин у середній оболонці [42]. Особливо схильні до спазму артерії у дітей віком до 10 років [31]. Імовірно, тому при травмі у 9 - 25\% дітей за наявності симптомів ішемії тканин кінцівок вдається уникнути втручання на судинах $[3,4$, 14, 31].

Таким чином, дані літератури щодо травми артерій у дітей обмежені через невисоку частоту. Травма артерій у дітей виникає внаслідок ятрогенних або неятрогенних чинників, ятрогенна травма виникає в медичних закладах під час проведення діагностичних чи лікувальних маніпуляцій, частіше у маленьких дітей; неятрогенна виникає вдома, на дворі, спортивних майданчиках, у школі, iї частота збільшується 3 віком. Травма артерій неминуча під час ендоваскулярних процедур у дітей молодшого віку, спричиняє тромбоз, ішемію тканин кінцівки, артеріовенозну норицю, псевдоаневризму. Неятрогенне ушкодження артерій супроводжує травму кінцівок і тулуба, характеризується значним клінічним різноманіттям.

\section{REFERENCES}

1. Allen CJ, Straker RJ, Tashiro J, Teisch LF, Meizoso JP, Ray JJ, et al. Pediatric vascular injury: experience of a level 1 trauma center. J Surg Res. 2015;196(1):1-7.

2. Barmparas G, Inaba K, Talving P, David J-S, Lama L, Plurad D, et al. Pediatric vs adult vascular trauma: a National Trauma Databank review. J Pediatr Surg. 2010;45(7):1404-12.

3. Corneille MG, Gallup TM, Villa C, Richa JM, Wolf SE, Myers JG, et al. Pediatric vascular injuries: acute management and early outcomes. J Trauma. 2011;70(4):823-8.

4. Jaipuria J, Sagar S, Singhal M, Bagdia A, Gupta A, Kumar S, et al. Paediatric extremity vascular injuries - experience from a large urban trauma centre in India. Injury. 2014;45(1):176-82.

5. Klinker DB, Arca MJ, Lewis BD, Oldham KT, Sato TT. Pediatric vascular injuries: patterns of injury, morbidity, and mortality. J Pediatr Surg. 2007;42(1):178-83.

6. Tshifularo N, Moore SW. Surgical intervention in vascular trauma in children. Pediatr Surg Int. 2012;28(4):375-8.
7. Bergqvist D, Karacagi S, Westman B. Paediatric arterial trauma. Eur J Surg. 1998;164(10):723-31.

8. Mommsen P, Zeckey C, Hildebrand F, Frink M, Khaladj N, Lange N, et al. Traumatic extremity arterial injury in children: epidemiology, diagnostics, treatment and prognostic value of Mangled Extremity Severity Score. J Orthop Surg Res. 2010;5:25.

9. Ammar AAR. Peripheral arterial injuries in pediatric age group. J Korean Soc Traumatol. 2016;29(2):37-42.

10. Bambini DA. Vascular injuries. In: Arensman RM, Bambini DA, Almond PS, editors. Pediatric Surgery. Landes Bioscience; 2000. ISBN: 1-57059-499-6.

11. Lin PH, Dodson TF, Bush RL. Surgical intervention for complications caused by femoral artery catheterization in pediatric patients. $\mathrm{J}$ Vasc Surg. 2001;34(6):1071-8.

12. Nazem M, Beigi A-A, Sadeghi AM-M, Masoudpour H. Non iatrogenic paediatric vascular trauma of the extremities and neck. Afr $\mathrm{J}$ Paed Surg. 2009;6(1):35-9. 
13. Silva MAM, Burihan MC, Barros OC, Nasser F, de Assis FA, Ingrund FC, et al. Trauma vascular na população pediátrica. J Vasc Brasil. 2012;11(3):199-205.

14. Wahlgren C-M, Kragsterman B. Management and outcome of pediatric vascular injuries. J Trauma Acute Care Surg. 2015;79(4):563-7.

15. Rodríguez-Montalbán A, Lobato-Andrés M, Acosta-Espeleta E, Gesto-Castromil E. Traumatismos vasculares en edad pediátrica. Características singulares y evolución a largo plazo. Angiologia. 2007;59(2):65-76.

16. Vitiello R, McCrindle BW, Nykanen D, Freedom RM, Benson LN. Complications associated with pediatric cardiac catheterization. J Am Coll Cardiol. 1998;32(5):1433-40.

17. Dogan OF, Demircin M, Ucar I, Duman U, Yilmaz M, Boke E. latrogenic brachial and femoral artery complications following venipuncture in children. Heart Surg Forum. 2006;9(4):675-80.

18. Yilmaz M, Dogan OF, Guvener M, Serterr T. Pseudoaneurysm of the popliteal artery in a child: an unusual complication of reconstruction of traumatic tibial fracture using Kirschner wire. Ulus Travma Acil Cerrahi Derg. 2010;16(1):90-1.

19. Andraska EA, Chen H, Jackson TO, Gallagher KA, Eliason JL, Coleman DM. Natural history of iatrogenic pediatric femoral artery injury. Abstracts Accepted for Presentation during the 25th Annual Winter Meeting Vascular and Endovascular Surgery Society. 2015;29(4):6345.

20. Matos RI, Holcomb JB, Callahan C, Spinella PC. Increased mortality rates of young children with traumatic injuries at a US army combat support hospital in Baghdad, Iraq, 2004. Pediatrics. 2008;122(5):95966.

21. Gamba P, Tchaprassian Z, Verlato F, Verlato G, Orzali A, Zanon GF. latrogenic vascular lesions in extremely low birth weight and low birth weight neonates. J Vasc Surg. 1997;26(4):643-6.

22. Kumar R, Trikha V, Malhotra R. A study of vascular injuries in pediatric supracondylar humeral fractures. J Orthop Surg. 2001;9(2):37-40.

23. Ledbetter DJ, Hall DG. Traumatic arteriovenous fistula: a complication of amniocentesis. J Pediatr Surg. 1992;27(6):720-1.

24. Gans I, Baldwin KD, Levin LS, Nance ML, Chang B, Kovach SJ, et al. A lower extremity musculoskeletal and vascular trauma protocol in a children's hospital may improve treatment response times and appropriate microvascular coverage. J Orthop Trauma. 2015;29(5):239-44.

25. Dua A, Via KA, Kreishman P, Kragh JF, Spinella PC, Patel B, et al. Early management of pediatric vascular injuries through humanitarian surgical care during U.S. military operations. J Vasc Surg. 2013;58(3):695-700.

26. Villamaria CY, Morrison JJ, Fitzpatrick CM, Cannon JW, Rasmussen TE. Wartime vascular injuries in the pediatric population of Iraq and Afghanistan: 2002-2011. J Pediatr Surg. 2014;49(3):428-32.
27. Chamoun RB, Mawad ME, Whitehead WE, Luerssen TG, Jea A. Extracranial traumatic carotid artery dissections in children: a review of current diagnosis and treatment options. J Neurosurg Pediatrics. 2008;2:101-8.

28. Lambropoulos V, Lazaridis I, Melas N, Kepertis C, Anastasiades K, Spyridakis I. Penetrating neck trauma in a 4-year-old child. Case Reports in Clinical Medicine. 2015;4:145-50.

29. Tiao GM, Griffith PM, Szmuszkovicz GR, Mahour GH. Cardiac and great vessel injuries in children after blunt trauma: an institutional review. J Pediatr Surg. 2000;35:1656-60.

30. Harris LM, Hordines J. Major vascular injuries in the pediatric population. Ann Vasc Surg. 2003;17(3):266-9.

31. Shah SR, Wearden PD, Gaines BA. Pediatric peripheral vascular injuries: a review of our experience. J Surg Res. 2009;153(1):162-6.

32. De Virgilio C, Mercado PD, Arnell T, Donayre C, Bongard F, White R. Noniatrogenic pediatric trauma: a ten year experience at a level I trauma center. Am J Surg. 1997;63(9):781-4.

33. Wolf YG, Reyna T, Schropp KP, Harmel RP. Arterial trauma of the upper extremity in children. J Trauma. 1990;30(7):903-5.

34. Dalsing MC, Cikrit DF, Sawchuk AP. Open surgical repair of children less than 13 years old with lower extremity vascular injury. J Vasc Surg.2005;41(6):983-98.

35. Fayiga YJ, Valentine J, Myers SI, Chervu A, Rossi P, Clagett GP. Blunt pediatric vascular trauma: Analysis of forty-one consecutive patients undergoing operative intervention. Ibid. 1994;20(3):419-25.

36. Coppola CP, Leininger BE, Rasmussen TE, Smith DL. Children treated at an expeditionary military hospital in Iraq. Arch Pediatr Adolesc Med.2006;160(9):972-6.

37. Peter SD, Ostlie DJ. A review of vascular surgery in the pediatric population. Pediatr Surg Int. 2007;23(1):1-10.

38. Chen W, Su Y, Zhang Q, Zhan Y, Smith WR, Maa L, et al. A proposed new system of coding and injury classification for arteries in the trunk and extremities. Injury.2012;43(9):1539-46.

39. Sciarretta JD, Macedo FIB, Chung EL, Otero CA, Pizano LR, Namias $\mathrm{N}$. Management of lower extremity vascular injuries in pediatric trauma patients: A single level I trauma center experience. J Trauma. 2014;76(6):1386-9.

40. Knudson MM. Commentary on "Vascular Injuries in the Young". Perspect Vasc Surg Endovasc Ther. 2011;23(2):111.

41. Mavrogenis AF, Panagopoulos GN, Kokkalis ZT, Koulouvaris P, Megaloikonomos PD, Igoumenou $\mathrm{V}$, et al. Vascular injury in orthopedic trauma. Orthopedics.2016;39(4):249-59.

42. Bendeck MP, Keeley FW, Langille BL. Perinatal accumulation of arterial wall constituents: relation to hemodynamic changes at birth. Am J Physiol. 1994;267(6):2268-79. 